\title{
The hidden prevalence of leprosy: a comparative study between two Brazilian cities
}

\author{
Tânia Rita Moreno de Oliveira Fernandes ${ }^{1}$ \\ (iD) Anderson de Almeida Pereira ${ }^{2}$ \\ (iD Lara Sodré Cardoso 3 \\ (iD Valdir Pereira Alves Filho ${ }^{3}$ \\ (DLuiz Sergio Nunes de Rezende Junior ${ }^{3}$ \\ (iDCarlos Dornesl Freire de Souza ${ }^{4}$
}

\begin{abstract}
1. PhD e Docente na Universidade Federal do Vale do São Francisco (UNIVASF), Petrolina, PE, Brasil. 2. Universidade Federal do Vale do São Francisco (UNIVASF), Petrolina, PE, Brasil. 3. Colegiado de Medicina, Universidade Federal do Vale do São Francisco (UNIVASF), Petrolina, PE, Brasil. 4. Complexo de Ciências Médicas e Enfermagem, Departamento de Medicina, Núcleo de Estudos em Medicina Social e Preventiva, Universidade Federal de Alagoas (UFAL), Maceió, AL, Brasil.
\end{abstract}

\section{SUMMARY}

OBJECTIVE: We compared the hidden prevalence of leprosy in two Brazilian cities with distinct differences regarding geographic region and socio-economic development profile, namely, Juazeiro, Bahia and Joinville, Santa Catarina.

METHODS: A retrospective epidemiological study based on secondary data obtained from leprosy case notifications in the cities of Juazeiro-BA and Joinville-SC, 2007-2017. To calculate hidden prevalence, we used the method proposed by Gil Suárez and Lombardi.

RESULTS: Joinville had 105 cases of leprosy that went undiagnosed (addition of $42.0 \%$ to the registered prevalence). For Juazeiro, it was estimated that 295 cases went undiagnosed (addition of $18.9 \%$ ).

CONCLUSION: Joinville presents a higher hidden prevalence than Juazeiro.

KEYWORDS: Leprosy. Epidemiology. Cross-sectional studies. Prevalence.

\section{INTRODUCTION}

Leprosy is an infectious, chronic, neglected disease, whose etiological agent is Mycobacterium leprae. It is an obligate intracellular parasite with an affinity for the skin and peripheral nerves, causing dermatological and neurological lesions and deformities, depending on the immunogenic potential of the bacillus and the human organism's response time'.
Brasil holds the first place worldwide in detection coefficient and the second place in absolute number of new registered cases, after India. In 2016, there were 214,783 new cases of leprosy worldwide, which represents a detection rate of 2.9/100,000 population, according to the WHO. This year, Brasil reported 25,218 new cases, with a detection rate of

DATE OF SUBMISSION: 06-Feb-2020

DATE OF ACCEPTANCE: 21-Apr-2020

CORRESPONDING AUTHOR: Carlos Dornels Freire de Souza

Departamento de Medicina, Universidade Federal de Alagoas, Rodovia AL-115 s/n, Bom Sucesso, AL, Brasil - 57309-005

Tel: +55 82 3214-1100 / +55 87 99622-0698

E-mail: carlos.freire@arapiraca.ufal.br 
$12.2 / 100,000$ population. The country is thus classified as highly endemic ${ }^{2,3}$. Over the past decades, there has been an effort by the Brazilian government to diminish the disease's impact; however, in the Northeast, North, and Central-West Regions, epidemiological indicators demonstrate that the disease is far from being eliminated as a public health problem ${ }^{3,4}$.

When analyzing the history of leprosy in Brasil, it is possible to observe that, although there has been an important reduction in the prevalence of the disease, the rate of detection has not effectively diminished. This reality is explained by the hidden endemic, the deficiency of public assistance programs, the precarious state of public health services, treatment abandonment, low level of public awareness, late diagnosis, the advent of sequelae and, consequently, the high burden of social prejudice which accompanies the disease ${ }^{5}$. It is believed that, to this day in Brasil, approximately one-third of notified patients with leprosy receive irregular treatment or abandon treatment, thus developing bacilli that are resistant to medication ${ }^{6}$.

In the state of Bahia, in 2015, 2,548 new cases of leprosy were reported, with a detection coefficient of 16.76 new cases/100,000 population ${ }^{7}$. In the same year, in the state of Santa Catarina, 171 new cases were reported, with a detection coefficient of 2.51/100,000 population $^{8}$. In 2015, 133 new cases were notified in the city of Juazeiro, Bahia, with a detection coefficient of 60.92/100,000 population, and 20 new cases were notified in Joinville, Santa Catarina (3.56/100,000 population). Thus, according to the parameters indicated by the Ministry of Health, Juazeiro has not yet reached the goal of eliminating leprosy as a public health problem; whereas in Joinville-SC, leprosy appears to be eliminated, that is, with a prevalence $<1.0 / 10,000^{9}$.

The aim of this study is to compare the hidden prevalence of leprosy in the cities of Juazeiro, Bahia, and Joinville, Santa Catarina, 2007-2017.

\section{METHODS}

This is a retrospective epidemiological study based on secondary data obtained from leprosy case notifications in Brasil's Notifiable Diseases Information System (SINAN, acronym in Portuguese) and DATASUS, in the cities of Juazeiro, Bahia, and Joinville, Santa Catarina, from 2007 to 2017, to calculate the detection coefficient, percentage of cases with disability grades, and hidden prevalence.
The estimated hidden prevalence was calculated using the method proposed by Gil Suárez and Lombardi $^{\mathbf{1 0}}$ and indicated by the PAHO and the WHO, which is based on the assumption that diagnoses of cases with physical disabilities indicate late detection and, thus, the presence of undiagnosed cases within a determined area. Accordingly, calculations are obtained using the following coefficients:

1. Annual percentage of cases with disability grades $=$ cases with disability / cases evaluated.

2. Annual estimated hidden prevalence $=$ new cases $\times$ percentage of cases with disabilities.

Forms used by healthcare professionals at the moment of patient diagnosis to evaluate the disability grade were filled out in accordance with the parameters stipulated by the Ministry of Health ${ }^{9}$. The following criteria were considered: grade 0 , there is no neural involvement in the eyes, hands or feet; grade 1 , there is a decrease or loss of sensation; and grade 2 , presence of disabilities and deformities such as lagophthalmos, claws, bone resorption, drooping hands and feet, among others 9 .

This study did not require approval from the ethics committee as it used open public domain data without the identification of individuals.

\section{RESULTS}

Between the years 2007 and 2017, in the city of Juazeiro, Bahia, 1,561 new cases of leprosy were notified, corresponding to an average detection coefficient of 65 cases/100,000 population. The detection coefficient in the general population decreased from $79.0 / 100,000$, in 2007, to 51.9/100,000 in 2017. The proportion of individuals with physical disabilities was greater than $10 \%$ in all years of the time series, reaching $27.6 \%$ in 2008 (Figure 1).

The number of new cases of leprosy showed no large variations during the study period, with an arithmetic mean of 142 cases per year. During the study period, 208 (13.3\%) patients were diagnosed with disability grade 1, and $81(5.2 \%)$ were diagnosed with grade 2 . Furthermore, $28(1.8 \%)$ patients were not assessed for their disability grade at the time of diagnosis (Table 1).

When analyzing the percentage of cases of patients with disabilities in relation to the number of cases evaluated, the highest percentage of patients with some disability grade was observed in 2008 , when $27 \%$ of the 159 new cases notified presented some degree of disability; on the other hand, in 2015, there was a 
significant drop in the number of cases of patients diagnosed with disabilities which were registered in only $11.3 \%$ of the 133 new cases (Table 1 ).

Making use of the method proposed by Gil Suárez and Lombardi ${ }^{10}$, it was estimated that approximately 295 cases of leprosy were not diagnosed and/or registered between the years of 2007 and 2017, in Juazeiro, Bahia. This number would represent an addition of $18.9 \%$ to the registered prevalence and would result in a real prevalence of 1,856 cases during the period. This result was obtained by the sum of the known prevalence (1,561 cases) and the hidden prevalence

FIGURE 1. DETECTION RATE IN GENERAL POPULATION (A) AND PERCENTAGE OF DISABLED PATIENTS - DEGREE 1 AND 2 (B) IN THE PERIOD FROM 2007 TO 2017 IN JUAZEIRO-BA AND JOINVILLE- SC.
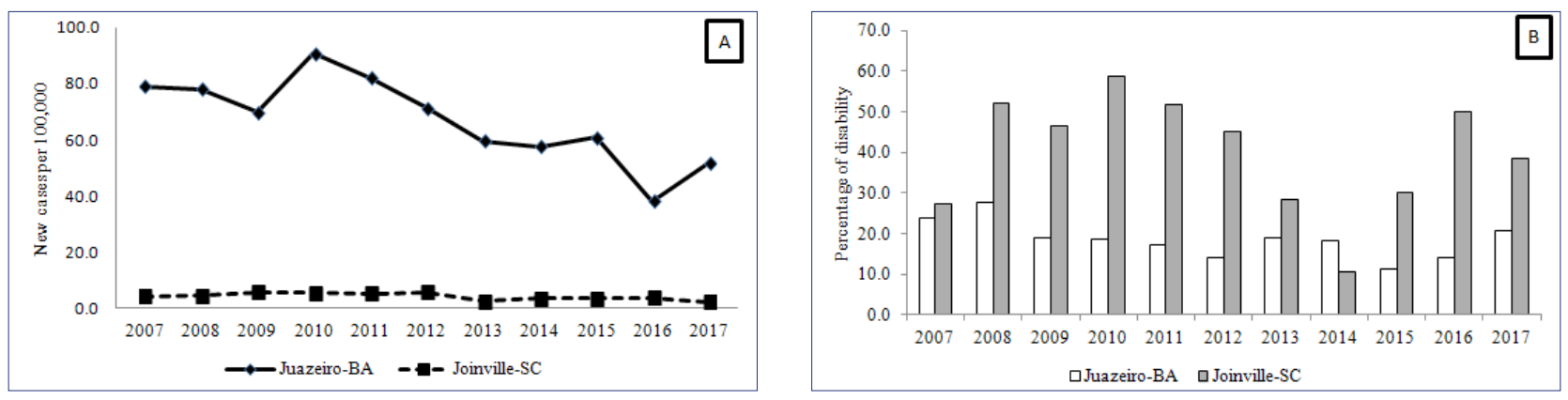

TABLE 1. NUMBER AND PERCENTAGE OF NEW CASES OF LEPROSY AND DEGREE OF DISABILITY FROM 2007 TO 2017 IN JUAZEIRO-BA AND JOINVILLE-SC.

\begin{tabular}{|c|c|c|c|c|c|}
\hline \multicolumn{6}{|c|}{ (A) Juazeiro, Bahia } \\
\hline \multirow{2}{*}{ Year of diagnosis } & Degree zero & Degree 1 & Degree 2 & Not rated & \multirow{2}{*}{ Total } \\
\hline & $n(\%)$ & $n(\%)$ & $n(\%)$ & $n(\%)$ & \\
\hline 2007 & $117(73.6)$ & $34(21.4)$ & $3(1.9)$ & $5(3.1)$ & 159 \\
\hline 2008 & $113(71.1)$ & $29(18.2)$ & $14(8.8)$ & $3(1.9)$ & 159 \\
\hline 2009 & 115 (79.9) & $20(13.9)$ & $7(4.9)$ & $2(1.4)$ & 144 \\
\hline 2010 & $152(80.4)$ & $27(14.3)$ & $8(4.2)$ & $2(1.1)$ & 189 \\
\hline 2011 & $142(82.1)$ & $23(13.3)$ & $7(4.0)$ & $1(0.6)$ & 173 \\
\hline 2012 & $129(84.9)$ & $14(9.2)$ & $7(4.6)$ & $2(1.3)$ & 152 \\
\hline 2013 & $98(76.6)$ & $12(9.4)$ & $11(8.6)$ & $7(5.5)$ & 128 \\
\hline 2014 & 99 (79.2) & $191(5.2)$ & $3(2.4)$ & $4(3.2)$ & 125 \\
\hline 2015 & $116(87.2)$ & $7(5.3)$ & $8(6.0)$ & $2(1.5)$ & 133 \\
\hline 2016 & $72(85.7)$ & $8(9.5)$ & $4(4.8)$ & $0(0.0)$ & 84 \\
\hline 2017 & 91(79.1) & $15(13.0)$ & $9(7.8)$ & $0(0.0)$ & 115 \\
\hline Total & $1244(79.7)$ & $208(13.3)$ & $81(5.2)$ & $28(1.8)$ & 1561 \\
\hline \multicolumn{6}{|c|}{ (B) Joinville, Santa Catarina } \\
\hline \multirow{2}{*}{ Year of diagnosis } & Degree zero & Degree 1 & Degree 2 & Not Rated & \multirow{2}{*}{ Total } \\
\hline & $n(\%)$ & $n(\%)$ & $n(\%)$ & $n(\%)$ & \\
\hline 2007 & $16(72.7)$ & $3(13.6)$ & $3(13.6)$ & $0(0.0)$ & 22 \\
\hline 2008 & $11(47.8)$ & $8(34.8)$ & $4(17.4)$ & $0(0.0)$ & 23 \\
\hline 2009 & $16(53.3)$ & $11(36.7)$ & $3(10.0)$ & $0(0.0)$ & 30 \\
\hline 2010 & 11(37.9) & $17(58.6)$ & $0(0.0)$ & $1(3.5)$ & 29 \\
\hline 2011 & $13(48.1)$ & $13(48.1)$ & $1(3.7)$ & $0(0.0)$ & 27 \\
\hline 2012 & $17(54.8)$ & $8(25.8)$ & $6(19.4)$ & $0(0.0)$ & 31 \\
\hline 2013 & $9(64.3)$ & $2(14.3)$ & $2(14.3)$ & $1(7.1)$ & 14 \\
\hline 2014 & $17(89.5)$ & $0(0.0)$ & $2(10.5)$ & $0(0.0)$ & 19 \\
\hline 2015 & $13(65.0)$ & $4(20.0)$ & $2(10.0)$ & $1(5.0)$ & 20 \\
\hline 2016 & $10(45.5)$ & $4(18.2)$ & $7(31.8)$ & $1(4.5)$ & 22 \\
\hline 2017 & $8(61.5)$ & $3(23.1)$ & $2(15.4)$ & $0(0.0)$ & 13 \\
\hline Total & 141(56.4) & $73(29.2)$ & $32(12.8)$ & $4(1.6)$ & 250 \\
\hline
\end{tabular}

Source: SINAN leprosy database, 2007-2017. 
FIGURE 2. PERCENTAGE OF HINDDEN LEPROSY IN JUAZEIRO, BAHIA, AND IOINVILLE, SANTA CATARINA, IN THE PERIOD FROM 2007-2017

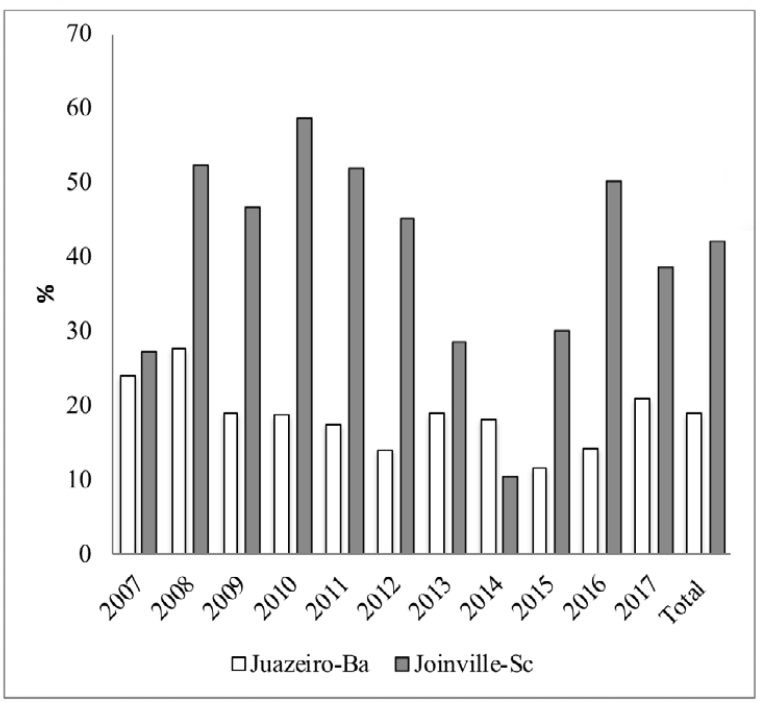

(295 cases). In this case, it is also possible to affirm that $15.9 \%$ of people affected with leprosy went undiagnosed and, therefore, untreated.

In Joinville-SC, 250 new cases of leprosy were registered with a detection coefficient of 4.28/100,000 population. Throughout the time series, the detection coefficient decreased from 4.4/ 100,000 in 2007 to $2.3 / 100,000$ in 2017 . The percentage of disabled people reached $58.6 \%$ of new diagnoses in 2010 (Figure 1). Additionally, during the study period, 105 (42.0\%) patients were diagnosed with some disability grade, 73 (29.2\%) patients with disability grade 1 , and 32 (12.8\%) with grade 2 (Table 1 ).

When calculating the hidden prevalence in Joinville by the method proposed by Gil Suárez and Lombardi ${ }^{10}$, it was shown that 105 cases of leprosy went undiagnosed and/or unregistered between 2007 and 2017. This represents an addition of $42.0 \%$ to the registered prevalence and a real prevalence of 355 cases, making it possible to estimate that $29.6 \%$ of people affected with leprosy went undiagnosed and untreated during the period (Figure 2).

\section{DISCUSSION}

One of the problems which programs for controlling and combating leprosy face is that of determining the magnitude of the disease within their area in order to establish public policies capable of dealing with this serious problem. This study has shown evidence that the cities of Juazeiro, Bahia, and Joinville, Santa Catarina, although distinctly different in terms of geographic location and economic and social situation, present detection coefficients which are, respectively, very high and average, as well as a high proportion of cases diagnosed with some disability grade, especially grade 1 . The evaluation of physical disability grade is an essential procedure in the initial approach to patients receiving healthcare services for leprosy"1.

Considering that leprosy is an endemic disease in Brasil, the need for more efficient control strategies within national territory is clear. Examples of such strategies include increasing access to basic healthcare, qualifying professionals to recognize signs and symptoms of the pathology, and developing educational actions in healthcare that will make it possible to diagnose and treat more cases earlier ${ }^{11}$. The disease is usually associated with regions with low socio-economic indexes; however, the observation that Joinville presents a considerable detection rate and an elevated hidden prevalence is contrary to what would be expected, given that, according to municipal human development index (MHDI) data from 2012 to 2017, the city had a value of 0.809 , which is considered very high by the United Nations (UN), and it held the $21^{\text {st }}$ position in the ranking of Brazilian cities ${ }^{12}$.

Juazeiro, on the other hand, presented an MHDI of 0.677 , considered average, and it held the $2,503^{\text {rd }}$ position in the ranking, during the same period ${ }^{12}$. Keeping in mind that the fundamental parameters of MHDI are per capita income, education, and life expectancy (characteristics of regions that are socio-economically well developed), Joinville could be considered a city with good health conditions ${ }^{12}$. A disease related to poverty would, thus, be expected to have lower rates of detection and hidden prevalence, in light of the high quality of life, more health information available to the public and, consequently, more access to services provided to the population ${ }^{13}$.

Juazeiro is a reference center for the diagnosis of cases of leprosy, not only in the Vale do São Francisco Region, but also in the state of Bahia. It has, for a few decades, had a Regional Reference Center, where a leprosy specialist, dermatologist, physical therapist, and epidemiological surveillance team work together and are responsible for a significant part of diagnoses, as verified by the high detection coefficient and the high incidence observed in this article's data analysis and according to information from the local secretary of health ${ }^{7,14}$. As seen in the tables, the problem persists for a considerable percentage of patients who receive 
a late diagnosis when they already present a disability grade, likely due to the absence of investment in health education by public institutions and to the rotation of the teams that have already been trained to manage this disease, which entails a delay in carrying out the diagnosis and early treatment. This problem ends up negatively influencing the context in which the disease is combated and eliminated, contributing to an increase in the incidence and rate of detection, given that untreated patients are important sources of transmission of the etiological agent ${ }^{14}$.

In the state of Santa Catarina, Joinville is the city with the highest number of cases of leprosy. The municipality has a Municipal Sanitary Unit Leprosy Program, which provides care and treatment through the Unified Health System. The team that provides regional support is composed of medical doctors, nurses, psychologists, physical therapists, and social workers. In addition to this program that has been made available, the population also has access to healthcare in the form of diagnosis and treatment at Basic Healthcare Units, as well as home follow-up by community health agents, thus guaranteeing integral care. Notwithstanding the strategies developed in this municipality for combating the disease, gaps still exist, both on public healthcare services and due to the population's lack of knowledge regarding the disease ${ }^{15}$.

In order to evaluate the health levels of a population, the absolute values of cases of a disease or injury should not be utilized, because they do not take the population size into consideration. For this reason, health indicators have been constructed in the form of ratios ${ }^{15}$. In this context, when analyzing the absolute values of the city of Joinville, a considerably lower number of cases was observed, with a prevalence rate of 0.12 per 10,000 population, which is considered low; in contrast, the average detection coefficient was
4.28 per 100,000 population, which classifies it as a medium endemic city ${ }^{2,14}$. Despite these coefficients, this city has a considerable hidden prevalence, as shown in the observed data. These values reflect problems on the operational level, showing that, notwithstanding efforts to eliminate the disease over the past decades, there have been irregularities in the work of the teams responsible for diagnosis and follow-up, both at the primary healthcare units and at the reference units ${ }^{14}$. In addition to this, many patients either do not know the signs and symptoms of this disease or they believe that it no longer exists, especially since this is a city with high socio-economic development. This, therefore, provides evidence of the need to continue investing in health policies in this region.

\section{CONCLUSION}

In relation to the panorama presented by these cities, we have observed a detection rate capable of impacting continuity of transmission in both areas, with a high hidden prevalence of the disease, especially in Joinville-SC. This means that it is necessary to undertake efforts not to relax disease control in these cities that have shown apparent decreases in the number of leprosy cases and to monitor closely areas where new cases with some disability grade are notified, given that these are, consequently, areas with a high hidden prevalence, in order to take steps, albeit at a late stage, toward the actual elimination of this disease as a public health problem.

\section{Author's Contribution}

All author's participated equaly in the concept development, study planning, data collection and analysis, discussion of the results, scientific drafting, as well as in the revision and approval of the final version of the work.

\section{RESUMO}

OBJETIVO: Comparar a prevalência oculta de hanseníase entre duas cidades brasileiras com diferenças distintas quanto à região geográfica e perfil de desenvolvimento socioeconômico, como Juazeiro, Bahia e Joinville, Santa Catarina.

MÉTODOS: Estudo epidemiológico retrospectivo baseado em dados secundários obtidos nas notificações de casos de hanseníase nos municípios de Juazeiro-BA e Joinville-SC, 2007-2017. Para o cálculo da prevalência oculta foi utilizado o método proposto por Gil Suárez e Lombardi.

RESULTADOS: Joinville teve 105 casos de hanseníase que não foram diagnosticados no período (adição de 42,0\% à prevalência registrada). Para Juazeiro, estimou-se que 295 casos não foram diagnosticados (adição de 18,9\%).

CONCLUSÃO: Joinville apresentou maior prevalência oculta que Juazeiro.

PALAVRAS-ChaVES: Hanseníase. Epidemiologia. Estudos transversais. Prevalência. 


\section{REFERENCES}

1. Mizoguti DF, Hungria EM, Freitas AA, Oliveira RM, Cardoso LP, Costa MB, et al. Multibacillary leprosy patients with high and persistent serum antibodies to leprosy IDRI diagnostic-1/LID-1: higher susceptibility to develop type 2 reactions. Mem Inst Oswaldo Cruz. 2015;110(7):914-20.

2. Henry M, Galan N, Teasdale K, Prado R, Amar H, Rays MS, et al. Factors contributing to the delay in diagnosis and continued transmission of leprosy in Brasil: an explorative, quantitative, questionnaire based study. PLoS Neg Trop Dis. 2016;10(3):e0004542.

3. Brasil. Ministério da Saúde. Secretaria de Vigilância em Saúde. Caracterização da situação epidemiológica da hanseníase e diferenças por sexo, Brasil, 2012-2016. Boletim Epidemiológico. 2018;49(4):1-10.

4. Souza CDF, Fernandes TRMO, Matos TS, Ribeiro Filho IM, Almeida GKA, Lima JCB, et al. Physical disability degree in the elderly population affected by leprosy in the state of Bahia, Brasil. Acta Fisiatr. 2017;24(1):27-32.

5. Monteiro MJSD, Santos GM, Barreto MTS, Silva RVS, Jesus RLR, Silva HJN. Perfil epidemiológico de casos de hanseníase em um estado do Nordeste brasileiro. Rev Aten Saúde. 2017;15(54):21-8.

6. Miranzi SSC, Pereira LHM, Nunes AA. Perfil epidemiológico da hanseníase em um município brasileiro, no período de 2000 a 2006. Rev Soc Bras Med Trop. 2010;43(1):62-7.

7. Gonçalves A. Realities of leprosy control: updatings scenarios. Rev Bras Epidemiol. 2013;16(3):611-21.

8. Governo do Estado de Santa Catarina. Secretaria de Estado da Saúde. Plano Estadual de ações estratégicas de vigilância, controle e prevenção da hanseníase no Estado de Santa Catarina. Período 2016 a 2020. Florianópolis:
Secretaria de Estado da Saúde; 2016. [cited 2020 Jan 28]. Available from: http://www.dive.sc.gov.br/conteudos/agravos/Documentos/Plano_Estadual_Hanseniase.pdf

9. Brasil. Ministério da Saúde, Secretaria de Vigilância em Saúde. Diretrizes para vigilância, atenção e eliminação da hanseníase como problema de saúde pública: manual técnico-operacional. Brasília: Ministério da Saúde; 2016. [cited 2020 Jan 28]. Available from: http://www.saude.pr.gov.br/arquivos/ File/Manual_de_Diretrizes_Eliminacao_Hanseniase.pdf

10. Gil Suárez RE, Lombardi C. Estimado de prevalência de lepra. Hansen Int. 1997;22(2):31-4

11. Alves ES, Oliveira LB, Araújo TME, Melo IV, Araújo RPS, Marques LMF. Perfil epidemiológico da hanseníase em um município do nordeste brasileiro: uma análise retrospectiva. Rev Pesqui Cuid Fundam. 2017;9(3):648-52.

12. Atlasbrasil.org.br [Internet]. Atlas de desenvolvimento humano no Brasil [cited 2019 Aug 28]. Available from: http://atlasbrasil.org.br

13. Ribeiro GC, Fabri ACOC, Amaral EP, Machado IE, Lana FCF. Estimativa da prevalência oculta da hanseníase na microrregião de Diamantina - Minas Gerais. Rev Eletr Enf. 2014;16(4):728-35.

14. Silva ME, Souza CD, Costa e Silva SP, Costa FM, Carmo RF. Epidemiological aspects of leprosy in Juazeiro-BA, from 2002 to 2012. An Bras Dermatol. 2015;90(6):799-805.

15. Sousa AN, Schoroeder G, editores. Educação em saúde a portadores de hanseníase: uma parceria com a unidade sanitária da cidade de Joinville [internet]. Centro Federal de Educação Tecnológica de Florianópolis: Unidade de Ensino de Florianópolis; 2005. 